\title{
Research on the "Five in One Integrity" Practical Teaching Model Based on the Cultivation of College Students' Creative Ability
}

\author{
Li Zhang \\ Harbin University of Commerce \\ Harbin 150028, China \\ Hongyan Xie \\ Harbin University of Commerce \\ Harbin 150028, China
}

\author{
Long Yin \\ Harbin University of Commerce \\ Harbin 150028, China \\ Li Zhao \\ Harbin University of Commerce \\ Harbin 150028, China
}

\begin{abstract}
Innovation and entrepreneurship is the strategic direction and inevitable trend of the training of talents in colleges and universities, and the talents of economic and management have played an important role in the process of innovation and entrepreneurship. Practice teaching is very important to cultivate students' talents and innovation ability. At present, the practical teaching of innovative talents in colleges and universities is not enough, the system is imperfect, the shortage of resources and the lack of teaching staff. The practice teaching should be perfected and strengthened from the perspective of "height, breadth and depth". According to the current situation of cultivating Undergraduate Colleges Students' ability of innovation and entrepreneurship, we put forward the new "five in one integrity" practice teaching mode. In which, practice teaching is the main body, exercise is the supplement, practice base is the platform, cultivating the project is the starting point, supporting the entrepreneurship is the goal. Practice has proved that the model has achieved good results, greatly enhance the overall quality of college students and innovative entrepreneurial ability.
\end{abstract}

Keywords-Innovation and Entrepreneurship; Five in One Integrity; Practical Teaching

\section{INTRODUCTION}

Colleges and universities have four functions: personnel training, dissemination of knowledge, scientific research, social services. Talent training is the most important function. Colleges and universities to achieve a comprehensive quality education, should focus on cultivating students' practical ability and innovation ability. Another well-known fact is that the foundation of innovation lies in practice. ${ }^{[1]}$ The general undergraduate colleges common school history is short, the comprehensive quality of students is not high, the majority of teachers are insufficient in the theory teaching as the core, practice teaching idea lags behind, the low proportion, efforts to train students' creative spirit and practical ability is not enough, which leads to the large majority of students' practical ability and employment ability is insufficient. Therefore, the practice of teaching and innovation and entrepreneurship ability is the training of ordinary undergraduate students to solve the problem of witch.
At present, the educational experts mostly carry out the research from the practice teaching development and the student innovation ability training method angle. How to combine practice teaching with innovation and entrepreneurship effectively, and how to realize the effective link between the progressive training of talents from practice teaching to innovation and entrepreneurship in the University for four years are seldom discussed. ${ }^{[2-4]}$ In view of this shortcoming, this paper will focus on the general undergraduate college management practice teaching and college students innovation and entrepreneurship ability training mode construction, and put forward the "five in one" innovative talents training new model.

\section{The CONSTRUCTION OF "FIVE IN ONE" PRACTICAL TEACHING MODEL}

Based on many years of practical experience in professional teaching of our school, in order to improve the students' practical ability and innovative spirit, committed to build and has formed a preliminary practice teaching, competition training, practice base, project training, entrepreneurial support "five in one" practice teaching mode. In which, practice teaching for all students, the race training to serve the students, the practice base for students to provide a good theoretical link with the actual platform, the project tends to have further development of space students, business support is aimed at a few students have entrepreneurial intention and business prospects. The whole audience shows the distribution of tower, five aspects are independent and organic convergence; cooperate with each other, as shown in the Fig.1. 


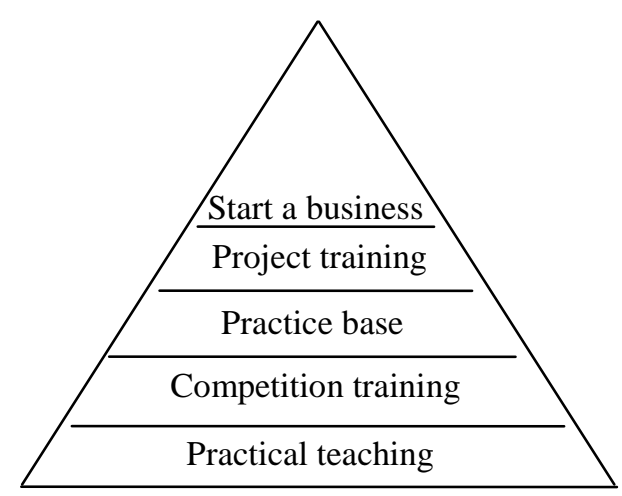

Fig. 1. "Five in one" practice teaching mode

\section{The Connotation And Practice of "Five In OnE" Mode}

\section{A. Practice teaching as the main body}

Classroom teaching is the basic way of knowledge learning and the basis of all the learning activities of university. At present, there are still many problems in classroom teaching, such as obsolete courseware, teaching a single way, textbooks and knowledge updates lag behind the actual needs of social exhibitions. In order to improve the quality of classroom teaching, efforts to reduce the emergence of "bow family", in addition to the theory of teaching more attention to practical teaching. Practical teaching is an effective supplement to theoretical teaching and an effective starting point for cultivating students' innovative spirit. In the course of practical teaching, most of the courses are required to adopt a set of progressive practice training mode, such as verification experiment, comprehensive experiment and curriculum design experiment, and pay attention to cultivating students' application innovation ability. Through the establishment of open innovation laboratory, so that students can achieve free choice of experimental projects and experimental time.

At the same time, we cooperate with many enterprises to build practice base, carry out deep school enterprise cooperation, arranging higher grade students to enter the enterprise to carry out practice training regularly. Transfer the practice place from the school to the enterprise, and expand the instructor team, not only ensure the cultivation of students' ability, but also to protect the students of the knowledge of the practice and master.

\section{B. Take competition exercise as supplement}

Throughout the international and domestic different types of disciplines race, its content and form, although not the same, but the basic can be divided into three types, which are quality improvement, professional strengthening and innovation and entrepreneurship ability to expand. The improvement of the basic quality of college students for any discipline, any professional personnel training is necessary. The main purpose of the professional intensive discipline competition is to improve the professional ability of students. Innovative Entrepreneurship Courses focus on examining students' use of years of accumulated knowledge of the process of innovation, but also to develop students divergent thinking and creative process. Several kinds of competition play a very important role in nurturing the teaching, and the basic purpose is to promote the cultivation of creative talents. The latter two kinds of competition have more influence on practical teaching. Students participate in these competitions not only require the necessary knowledge reserves, but also have a large number of laboratory equipment, competition drills and necessary venues. Therefore, the competition of discipline not only strengthens the professional quality of students, but also enables students to have an intuitive and comprehensive understanding of all aspects of enterprise transportation. Precisely because of this, discipline competition itself is not an end, and its real role is to deepen the students' grasp of the basic theoretical knowledge and the understanding of the mechanism behind the professional practice process.

\section{Take practice base as platform}

Teaching practice base is an important place for students of colleges and universities to participate in the practice and social practice. The construction of teaching practice base is directly related to the quality of practice teaching, and plays a very important role in the practical ability and creative ability of high-quality personnel. Schools and a number of well-known enterprises to build practice base, to carry out the depth of school-enterprise cooperation, regular arrangements for senior students into the enterprise practice training. Through "go out, please come in", the practice of transferring and guiding teachers team expansion, not only to ensure that students personality and ability to develop, but also to ensure that students of new skills in practice and master.

\section{Project cultivation as the starting point}

It is well known that any research program aimed at nurturing and enhancing students' practical ability and learning ability must pay attention to the research process. The project implementation is the best way to reflect the process of research, students in the implementation of the project process, whether it is to complete the project feasibility study, project planning and design, research report, the results of the exchange of content, the students encountered difficulties not only from the disciplines of knowledge, theoretical knowledge and will encounter social practice is not exactly the same confusion. Therefore, in the implementation of the project, can not blindly pursue the project results, but should pay attention to the process of research, in the process of learning to take the initiative to learn, learn teamwork, learn to understand the failure, learn to transform the results, learn to serve the community, which is to carry out project research the essence lies.

\section{E. Aim at starting a business}

Since the beginning of the 21st century, the innovative spirit and entrepreneurial desire of college students have become stronger. Many entrepreneurship typical come to the fore, to make a demonstration, leading a group talented college students with dream abandon the traditional employment concept, to join the entrepreneurial army. In recent years, more and more attention has been paid to the entrepreneurship of College students. Another important fact is that college students employment difficult, one of the important reasons is that university students have no personality, characteristics, there is no job competitive ability, so many students in recent years have chosen to achieve employment through 
entrepreneurship. At the same time, the state has also launched a series of entrepreneurial support policies, such as youth entrepreneurship, leading programs, public support funds, small and medium-sized micro enterprise support fund, etc.. A group of students will enter their own project into the school incubation incubator base, there are a large number of students who have graduated or are going to graduate, using their own competition and innovative results to start the entity business.

\section{APPLICATION SITUATION AND IMPLEMENTATION EFFECT}

\section{A. Optimize the cultivation of students}

Since the formation of the "five in one" practice teaching system since 2008, the implementation of the professional in the school, highly recognized by the students, we generally believe that: "five in one" practice teaching system for students to provide comprehensive capacity training a variety of options. Through a full range of practical lessons and training, in the process of combining theory with the actual understanding of the professional business content, the professional counterparts in the industry's work processes have a more in-depth understanding. In addition, they have developed the ability to take the initiative to think about problems, solve problems and collect, master, classify and analyze information ${ }^{[5]}$.

Through the practice teaching reform, students' practical ability and innovative ability have been improved obviously, students participate in extracurricular activities of the enthusiasm is also greatly improved, more than $50 \%$ of the extracurricular practice activities. Since 2008, under the careful guidance of the center and college teachers, students have won many awards in all kinds of practice innovation ability competition of Heilongjiang and national. Employers also give high evaluation to the effect of strengthening practical teaching in our university. In recent years, the employment rate of graduates majoring in economics and management has been stabilized at around 95\%. Employers generally believe that the practical ability, job adaptation ability, starting ability and cooperation ability of the graduates of economics and management specialty in our university are stronger. From the Graduate Employment Guidance Center graduates quality survey, the excellent and good rate of more than $97 \%$.

\section{B. The central connotation has been improved}

Since 2008, the center teachers undertake 4 national research projects, 14 provincial projects; more than 130 papers published in domestic and foreign academic journals, published monographs, teaching materials and translation of 16 . The center in the continuous improvement of the connotation construction of demonstration center, and strive to explore and innovation of practice teaching system of achievements have caused widespread concern in the community, since 2008 there have been teachers in more than 100 colleges and universities at home and abroad to visit the school, very much agree with reform practice curriculum system of economic management center transformation, and the achievements given the full affirmation. In addition, the center also received visits and exchanges from more than 10 foreign universities and leaders, which became an important window and platform for our foreign cooperation in running schools, which produced extensive radiation effects and enormous social benefits ${ }^{[6-8]}$.
Center to strengthen the construction of practice teaching achievements, has aroused the attention of the news media, many media are the center of teaching from multiple angles were reported, and the center as a typical model of innovation and entrepreneurship education for promotion. These special reports have promoted the successful experience of our school.

\section{CONCLUSION}

The new mode of "five in one" talents training, which is based on practical teaching, competition training, practice base, project cultivation and entrepreneurship support, has promoted the cultivation of innovative talents in our university. The students' practical ability, innovative thinking and entrepreneurial consciousness have been greatly improved. The subjects have achieved fruitful results, and the implementation of the project has been in good condition, and it has won a high reputation for the school. The proportion of students' scientific research projects and intellectual property rights has increased year by year, and the atmosphere of innovation and entrepreneurship in schools has been gradually strong. It meets the new expectations and requirements of the recent national and educational departments for college students in the new era. This model for other similar schools to carry out practical teaching and ability of college students, as well as innovative entrepreneurship training has some reference.

\section{ACKNOWLEDGMENT}

This work is supported by Hei Longjiang Province Project(SJGY20170056), Harbin University of Commerce Teaching Reform and Teaching Research(HSDJY201704(Z)): A Study on the "Five in One" Practical Teaching Model Based on the Cultivation of Innovative and Enterprising Ability of College Students in Commercial Colleges.

\section{REFERENCES}

[1] Xinghai Huang. On the Practical Teaching Mechanism of Innovation and Entrepreneurship Education in Colleges and Universities. Heilongjiang Researches on Higher Education. Vol. 259 (2016), p. 122124.

[2] Li Zhang, Liucheng Zhang, Fengxia Wang. Construction and practice of virtual simulation experimental teaching center for modern business operation. Experimental Technology and Management. Vol. 31 (2014), p. 1-4.

[3] Hao Chen. Practice Teaching Reform for the Cultivation of Innovative and Entrepreneurial Capacity. Experiment Science and Technology. Vol. 12 (2014), p. 140-143.

[4] Xiaohui Xu, Cao Lan, Dongxiang Zhang. System construction of virtual simulation experimental teaching platform on entrepreneurship in comprehensive universities. Laboratory Science. Vol. 19 (2016), p. 9093.

[5] Weiguo Wang, Jinhong Hu, Hong Liu. Dongxiang Zhang. Current Situation and Development of Virtual Simulation Experimental Teaching of Overseas Universities. Research and Exploration in Laboratory.. Vol. 34 (2015), p. 214-219

[6] Wang Weiguo. Construction Consideration and Suggestion of Virtual Simulation Experimental Teaching Center[J]. Research and Exploration in Laboratory. Vol. 32 (2013), p. 5-8.

[7] Li Ping, Mao Changjie, Xu Jin. Construction of the National Virtual Simulation Experiment Teaching Centers, Improving the Experimental Teaching informatization in Higher Education. Research and Exploration in Laboratory. Vol. 32 (2013), p. 24-29.

[8] $\mathrm{Xu}$ Xiaohui, Lan Cao, Zhang Dongxiang. System construction of virtual simulation experimental teaching platform on entrepreneurship in comprehensive universities. Laboratory Science. Vol. 19(2016), p. 90-93. 